
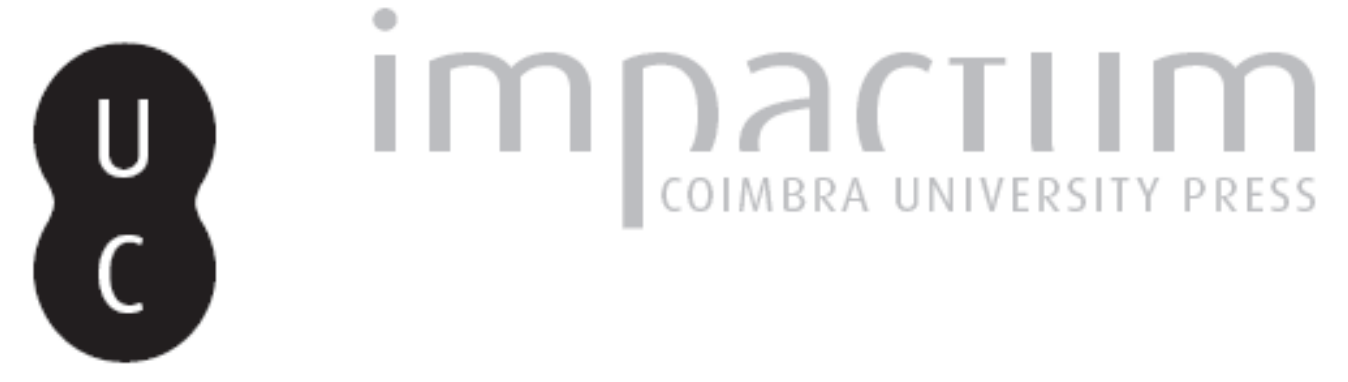

\title{
A utilização dos materiais cerâmicos de construção em Conimbriga
}

Autor(es): $\quad$ Triães, Ricardo; Correia, Virgílio H.; Coroado, João

Publicado por: Faculdade de Letras da Universidade de Coimbra

URL persistente:

URI:http://hdl.handle.net/10316.2/37668

DOI:

DOI:http://dx.doi.org/10.14195/1647-8657_41_6

Accessed : $\quad$ 26-Apr-2023 13:49:53

A navegação consulta e descarregamento dos títulos inseridos nas Bibliotecas Digitais UC Digitalis, UC Pombalina e UC Impactum, pressupõem a aceitação plena e sem reservas dos Termos e Condições de Uso destas Bibliotecas Digitais, disponíveis em https://digitalis.uc.pt/pt-pt/termos.

Conforme exposto nos referidos Termos e Condições de Uso, o descarregamento de títulos de acesso restrito requer uma licença válida de autorização devendo o utilizador aceder ao(s) documento(s) a partir de um endereço de IP da instituição detentora da supramencionada licença.

Ao utilizador é apenas permitido o descarregamento para uso pessoal, pelo que o emprego do(s) título(s) descarregado(s) para outro fim, designadamente comercial, carece de autorização do respetivo autor ou editor da obra.

Na medida em que todas as obras da UC Digitalis se encontram protegidas pelo Código do Direito de Autor e Direitos Conexos e demais legislação aplicável, toda a cópia, parcial ou total, deste documento, nos casos em que é legalmente admitida, deverá conter ou fazer-se acompanhar por este aviso.

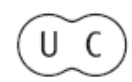




\section{CONIMBRIGA}

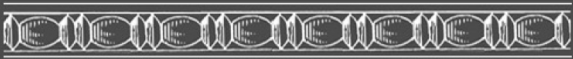

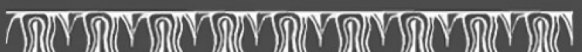
2

INSTITUTO DE ARQUEOLOGIA

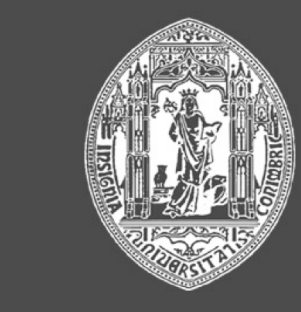

VOLUME XLI - 2002

F A C U L D A E D E LETRAS UNIVERSIDADE DE COIMBRA 
RICARDO TRIÃES

Universidade de Aveiro

VIRGílio H. CORREIA

Museu Monográfico de Conimbriga

JoÃo COROADO

Instituto Politécnico de Tomar

\section{A UTILIZAÇÃO DOS MATERIAIS CERÂMICOS DE CONSTRUÇÃO EM CONIMBRIGA \\ "Conimbriga" XLI (2002) p. 153-164}

RESUMO: Em Conimbriga, os materiais cerâmicos não são os mais utilizados na construção, sendo a pedra - calcário - disponível na zona em grande quantidade e de fácil exploração. Contudo, o material cerâmico nas suas diversas formas, por ser mais regular e permitir a produção em série de peças com formas específicas, facilita algumas soluções construtivas. Neste sentido apresenta-se a utilização dos materiais cerâmicos de construção e a funcionalidade de cada uma das formas.

Neste trabalho estuda-se principalmente a tipologia dos materiais cerâmicos de construção encontrados em diferentes aplicações, enquadrando-as no contexto de conservação e restauro de estruturas, realçando algumas diferenças no fabrico das várias peças, através das marcas e dimensões, que podem conduzir a informações relativas à sua produção e ao enquadramento socio-ambiental, das oficinas de olaria.

Neste estudo faz-se também a reflexão sobre a importância deste tipo de informação na conservação e restauro das estruturas desta civitas.

ABSTRACT: As limestone is plentiful and easily mined in the area of Conimbriga, ceramics are not amongst the most widely used construction materials. All the same, ceramic pieces, which could be produced and even 
mass-produced in precise shapes, often were the best solution for particular construction problems. Every type of construction ceramics, their use and function will be presented.

The study of the typology of ceramic construction materials, as used for different purposes, is emphasized. In addition minor differences in the production of these pieces such as variations of size, possible maker's stamps etc. are studied. These could lead to information about their production and/or the social place of the pottery workshops in the community.

We also look at the importance this information could have in connection with the conservation and restoration of the buildings of this civitas. 


\section{A UTILIZAÇÃO DOS MATERIAIS CERÂMICOS DE CONSTRUÇÃO EM CONIMBRIGA}

\section{A introdução dos materiais cerâmicos de construção em Conimbriga}

Os materiais cerâmicos de construção são uma introdução do período romano no nosso território. Encontrar uma cronologia precisa do início da utilização destes materiais em Conimbriga não se torna fácil. Contudo, através do registo arqueológico pretende-se fazer uma breve abordagem às cronologias apontadas para os níveis onde alguns destes materiais foram encontrados.

As campanhas de escavações arqueológicas realizadas pela equipa luso-francesa entre 1964 e 1971, dirigidas por Jorge Alarcão e Robert Etienne, permitiram pôr a descoberto e identificar as estruturas dos fora (augustano e flaviano), das termas do sul (augustanas e das remodelações da época de Trajano), da insula do vaso fálico e da insula ao norte das termas, ficando três insulae parcialmente escavadas (Alarcão e Etienne, 1977; 10-11).

Na zona do forum e das termas foram identificadas vestígios pré-romanos (estruturas habitacionais e diverso espólio) que se relacionam com a ocupação da Idade do Ferro neste local.

Este urbnismo pré-romano sobreviveu ainda às primeiras construções públicas augustanas, pois conservam-se ainda algumas destas zonas habitacionais, nomeadamente o "bairro da esplanada do templo flaviano" (Arruda, 1988-1989, 94). Estas estruturas não foram sistematicamente escavadas nas campanhas luso-francesas, ficando por escavar até 1988, quando A. M. Arruda aí efectuou 3 campanhas de escavação entre 1988 e 1989 (Arruda, 1988-1989; Arruda 1997).

As estruturas identificadas neste sector, o "bairro da esplanada do templo", foram identificadas como uma reconstrução posterior às de- 
molições efectuadas na zona da praça, basílica e cúria do forum augustano, imediatamente antes da construção deste (Arruda, 1988-1989; 94-95). Estes trabalhos, permitiram a escavação de níveis correspondentes à sua ocupação, principalmente no compartimento 7 (Arruda, 1988-1989; 97, fig. 2.1). Nestes níveis foram encontrados materiais romanos, "nomeadamente material de construção com cronologias que apontam para a fase inicial do Império" (Arruda, 1988-1989; 99).

Assim, pode dizer-se que com a chegada dos romanos a Conimbriga e através da ocupação do planalto, vão moldando os traços indígenas, aproveitando o urbanismo existente numa primeira fase, redimensionando-o na primeira grande transformação deste espaço que corresponde à fase augustana, com a construção do forum, das termas do sul e do aqueduto, tudo isto no final do séc. I a. C.

Terá sido provavelmente neste período que se iniciou a produção e utilização dos materiais cerâmicos de construção em Conimbriga.

\section{Materiais cerâmicos de construção}

\subsection{Matérias primas e processos de fabrico}

As matérias primas para o fabrico dos materiais cerâmicos de construção que se encontra em Conimbriga eram fundamentalmente argilas de origem local às quais se adicionavam saibro ou areia por forma a adequar as propriedades dos materiais cerâmicos aos fins a que se destinavam. As diferentes formas de materiais cerâmicos observadas eram, na sua maioria, obtidas por modelação da argila com formas de madeira sem fundo, de dimensões e formas variáveis, podendo moldar um ou mais de cada vez. A secagem fazia-se ao sol, em locais abertos e amplos e nas estações secas do ano. A cozedura destes materiais era feita em fornos cuja câmara poderia variar nas dimensões, em razão do volume de material e dos tipos em cada cozedura (Adam, 1989).

2.2. A produção de materiais cerâmicos de construção: oficinas, proprietários e operários

Em Conimbriga a produção de materiais cerâmicos de construção era maioritariamente propriedade de particulares. Contudo, J. Alarcão 
(1990), refere que poderão ter existido produções em oficinas municipais, pelo aparecimento no povoado mineiro de Três Minas, de uma telha com a marca AFL A(quae) FL(aviae) e em Conimbriga de um tijolo com a marca RPC R(es) $\mathrm{P}($ ublica $) \mathrm{C}$ (onimbrigensis), embora esta conclusão não seja segura. Alguns dos fornos de cerâmica de construção deste período, segundo J. Alarcão (1990), poderão ter pertencido a particulares, para auto-abastecimento, que eram depois abandonados ou destruídos (Alarcão, 1990). Porém, algumas marcas em tijolos, feitas após a modelação, com o barro ainda fresco, apontam para uma produção de cariz industrial, destinada ao mercado. As marcas em tijolos, tal como a associação às suas formas típicas, dispersam-se um pouco por todo o território, desconhecendo-se ainda por falta de estudos sistemáticos a possível produção em grandes oficinas (caso tenham existido), e os seus mercados (Alarcão, 1988; Alarcão, 1990).

Em Conimbriga, identificaram-se através das marcas em tijolos e telhas, vários proprietários de oficinas: Primus, Duatius, Avita, Fronto e Maelo, tal como alguns operários; Caletus, Nigellio, Tangenus, Agilio, Arlenus e Titus. Alguns destes proprietários também se dedicavam ao fabrico de pesos de tear e de recipientes cerâmicos (Alarcão, 1994).

Outras marcas, para além das epigrafadas, foram encontradas no decorrer deste trabalho. Algumas delas realizadas de forma involuntária durante a secagem: pegadas humanas de adulto e criança, pegadas de animais, cão (fig. 3) e cabra/ovelha e impressões de elementos vegetais, folha de oliveira (fig. 4) e cúpula de bolota?; sugerem um espaço rural, ou pluri-funcional, apontando para uma multi-actividade de alguns dos proprietários destas oficinas, cuja produção, nalguns casos era uma actividade sazonal.

A localização destas oficinas na zona de Conimbriga é ainda desconhecida, sendo certo situarem-se fora das muralhas, devido à necessidade de grandes espaços para armazenamento das matérias primas, (argila e areia), água, combustível e para a secagem e armazenamento dos materiais após cozedura.

\section{Utilização dos materiais cerâmicos de construção}

A utilização principal do tijolo é na alvenaria. Podem assim encontrar-se zonas de construção apenas em tijolo, como nalguns canteiros (fig. 5) e tanques dos peristilos das domus, ou construções em que o 
tijolo forma um paramento interno de revestimento dos muros (nalguns casos formando uma camada refractária), ou nas últimas fiadas dos muros em pedra, procedendo à sua regularização e também em alvenarias mistas de pedra e tijolo.

Uma outra utilização dos materiais cerâmicos é na construção de colunas. Nestas, as unidades são de formato triangular apresentando várias formas e dimensões. Assim encontram-se colunas em alvenaria nos peristilos de todas as domus escavadas e também nas insulae, em pequenos átrios e nos pórticos.

Nos hipocaustos das várias termas encontram-se estruturas em tijolo. Nos pilares e arcos de suporte das suspensurae, tal como na base destas e no pavimento do hipocauto.

Outra das zonas de aplicação do tijolo é nos praefurnia das várias termas e nos arcos que suportam as paredes das termas e que fazem a passagem do ar quente entre as várias divisões do hipocausto.

Também na canalização de esgotos e em pavimentos, que nalguns casos eram cobertos por opus signinum, o tijolo é bastante utilizado.

Existem ainda alguns arcos sobre os vãos (alguns deles reconstruções), funcionando como lintéis, usando apenas os materiais cerâmicos e argamassa.

O tijolo é ainda aplicado pontualmente e sem qualquer especificidade, apenas quando a solução tecnicamente o exige ou por forma a facilitar o trabalho, pois é muito mais regular e fácil de utilizar do que a pedra.

Também se observa o reaproveitamento de alguns materiais cerâmicos na construção, como o caso das tegulae em pavimentos ou o de imbrices nas canalizações.

\section{Tipologia}

As tipologias mais representativas em Conimbriga - pela diversidade de aplicações e número de exemplares - são os tijolos maciços rectangulares e quadrangulares, os tijolos de coluna (fig. 9) e os tijolos maciços em cunha (fig. 10), que se puderam classificar através das suas dimensões. Além destas tipologias, encontram-se ainda in situ e principalmente em reserva ou em exposição, mais 11 tipologias: tijolo maciço losangular, tijolo maciço hexagonal e tijolo maciço rectangular (todos de pequenas dimensões, utilizados em pavimentos), tijolo maciço 
paralelepipédico, tegula, imbrex, bobines, tegula mamata, tijolo de caixotão, manilhas (para canalizações de água) e elemento de conduta.

Tijolos maciços rectangulares: Dentro desta tipologia foram considerados 8 tipos com dimensões distintas;
A - 33 x 29,5 cm;
B - $40 \times 14,5 \mathrm{~cm}$
C - $40 \times 22,5 \mathrm{~cm}$;
D - $40 \times 27,5 \mathrm{~cm}$;
E - $42 \times 14 \mathrm{~cm}$;
$\mathrm{F}-42 \times 29 \mathrm{~cm}$
$\mathrm{G}-45 \times 29,5 \mathrm{~cm}$;
$\mathrm{H}-51 \times 29 \mathrm{~cm}$.

(a espessura não foi considerada neste trabalho para nenhuma das tipologias). Podem ser encontrados inteiros ou fragmentados, na construção de alvenarias, nas canalizações de esgotos, nos pavimentos, nos arcos, nos lintéis e em estruturas de combustão. Este tipo surge aplicado de uma forma propositada em construções ou reaproveitado sob a forma de fragmentos.

Tijolos maciços quadrangulares: Para este tijolo identificaram-se menos tipos. Embora as dimensões entre os tijolos de alguns tipos não sejam constantes consideraram-se 6 , com as seguintes dimensões de referência:

$$
\begin{aligned}
& \text { A }-17,5-18,5 \mathrm{~cm} ; \\
& \text { B }-22,5 \mathrm{~cm} ; \\
& \text { C }-36 \mathrm{~cm} ; \\
& \text { D }-39 \mathrm{~cm} ; \\
& \text { E - } 44 \mathrm{~cm} ; \\
& \text { F }-59 \mathrm{~cm} \text {. } \\
& \text { O tipo A é utilizado apenas nas pilae de suporte da suspen- }
\end{aligned}
$$
sura. As dimensões deste tijolo (bessalis) nas termas hispânicas, varia entre os 18-24 cm (Ochoa et al., 1999; 300). O tijolos do tipo E (sesquipedalis) constituem o plinto das colunas de um peristilo da casa dos repuxos. Os restantes tipos encontram-se na reserva do Museu. Contudo o tipo $\mathrm{F}$ (bipedalis), pelo distanciamento entre pilae do caldarium das termas do sul, serviram como base da suspensura do mesmo. 
Tijolos de coluna: Têm uma utilização mais específica, sendo apenas utilizados na construção de colunas. No conjunto dos tijolos estudados, registaram-se 3 tipos, inserindo-se em cada um deles vários grupos. Cada tipo foi definido pela sua forma, que associado com outros idênticos completam circunferências (a unidade repetitiva de crescimento do fuste da coluna, "pequeno tambor") relativamente perfeitas, com um número variável de tijolos. Pela medida da corda destes tijolos obtêm-se um dos lados de três figuras geométricas, o quadrado, o pentágono e o hexágono, ou seja, circunferências formadas por 4,5 ou 6 tijolos. Para além das diferenças entre estes 3 tipos, podem observar-se tijolos com variações de dimensão significativas dentro dos mesmos.

O tipo A é constituído por conjuntos de 4 tijolos que formam uma circunferência (apenas se indicam as medidas do raio e corda):

A1 - 14 x $19 \mathrm{~cm}$;

A $2-16 \times 22,2 \mathrm{~cm}$;

A $3-17$ x $24 \mathrm{~cm}$;

A4 - 20,5 x 28,5 cm;

A5 - 26,5 x $36 \mathrm{~cm}$.

O tipo B é constituído por conjuntos de 5 tijolos:

$\mathrm{B} 1-13,5 \times 15-15,5 \mathrm{~cm}$;

B2 - 15,5 - 16 x 18,2 cm;

B3 - $17-17,5 \times 20 \mathrm{~cm}$;

B4 - 19,5-20 × $23-23,5 \mathrm{~cm}$.

O tipo $\mathrm{C}$ é constituído por conjuntos de 6 tijolos:

C1 - 13,5 x $13 \mathrm{~cm}$;

C2 - 15 - 15,5 x $15-15,5 \mathrm{~cm}$;

$\mathrm{C} 3$ - 16 - 16,5 x 15,5-16,5 cm;

$\mathrm{C} 4-17,5-18 \times 17-17,5 \mathrm{~cm}$;

C5 - 20 x $19-19,5 \mathrm{~cm}$;

C6 - 26,5 - 27,5 x 26,5 - 27,5 cm.

Dentro desta tipologia registaram-se ainda alguns tijolos com formas e dimensões idênticas, mas que serviram para a construção das bases e dos capitéis, embora em menor número, não permitindo esta classificação. A utilização de colunas em alvenaria de tijolo dispersa-se um pouco pelos vários edifícios de Conimbriga, com maior incidência nos privados.

Tijolos maciços em cunha: Estes tijolos são tendencialmente quadrados, mais espessos numa das extremidades e em forma de cunha 
(cuneati). Pelo seu uso específico, a diversidade de tipos é muito menor. Considerou-se apenas um tipo, aceitando uma pequena variação das dimensões:

17 - 19 × $6-6,5 / 4,5-5 \mathrm{~cm}$.

A sua utilização apenas se verifica nas termas, mais concretamente na construção de arcos no hipocausto, para suporte da suspensura.

Encontrámos ainda in situ algumas tegulae em alvenarias, a cobrir esgotos, no pavimento do hipocausto das termas da muralha e imbrices em canalizações. Contudo, são raras estas situações e com poucos exemplares.

Foram ainda encontradas em Conimbriga algumas tipologias, que referimos anteriormente, mas das quais não existe registo in situ. É o caso dos tijolos paralelepipédicos, das bobines (pequenos cilindros cerâmicos, mais espessos nas extremidades e com um furo central) e de fragmentos de tegulae mamatae, todos utilizados na construção das paredes duplas das salas aquecidas das termas; os tijolos de caixotões que serviriam de revestimento do intradorso dos tectos ou abóbadas; as manilhas, tubos cerâmicos para a canalização da água; e um tijolo designado elemento de conduta (semelhante a uma tegula mas mais estreita), exemplar único em exposição no Museu Monográfico de Conimbriga.

Devemos considerar um outro conjunto de tijolos de pequenas dimensões que não existem in situ, mas que pela quantidade significativa de elementos, foi possível classificar em 3 tipos:

Tijolo maciço losangular: Apresentam a forma de um losango. Consideraram-se 2 tipos com dimensões suficientemente distintas, podendo indicar produções diferentes:

$$
\begin{aligned}
& A-10,5 \times 6,2 \times 3 \mathrm{~cm} ; \\
& B-12,5 \times 6 \times 3,8 \mathrm{~cm} .
\end{aligned}
$$

Tijolo maciço hexagonal: Apresentam a forma de um hexágono. Classificou-se apenas 1 tipo, com um diâmetro equivalente de 7,3 cm e $3 \mathrm{~cm}$ de espessura. 
Tijolo maciço rectangular: De forma rectangular, registaram-se 2 tipos:

$$
\begin{aligned}
& A-12,5 \times 4,2 \times 4 \mathrm{~cm} ; \\
& B-9-10 \times 4,5 \times 3 \mathrm{~cm} .
\end{aligned}
$$

Estes tijolos eram provavelmente utilizados em pavimentos. Nos vários trabalhos de escavação de Conimbriga não foram ainda identificados pavimentos com estes materiais, embora se encontrem em diversos sítios arqueológicos de época romana alguns de dimensões idênticas aos tipos referidos (Santonja, 1999; 80-81).

\section{Síntese final}

\subsection{Utilização/Tipologia}

Como se tem referido ao longo deste trabalho, verifica-se que existe uma determinada associação de algumas tipologias com a utilização nos edifícios. Por um lado, pela pouca utilização dos materiais cerâmicos em grandes construções, limitando os locais de aplicação, mas por outro lado são imprescindíveis noutros edifícios, estreitando esta relação entre as tipologias e a sua utilização. A pedra é o material de construção por excelência, mas condicionada a algumas alterações. A utilização dos materiais cerâmicos de construção ganha maior relevo quando se trata, entre outras, das coberturas de edifícios e nas termas, com utilizações muito específicas nas zonas aquecidas, onde são utilizadas várias tipologias e muitas delas de uso exclusivo (Dias, 1999; Ochoa et al., 1999).

O presente trabalho, ainda de forma incipiente, apontou alguns dados sobre a produção de materiais cerâmicos de construção e da importância da sua classificação. Centrando-se nos aspectos formais e dimensionais e analisando um número significativo de tijolos, preparam-se os estudos composicionais e texturais das pastas, na perspectiva do cruzamento destes resultados com as cronologias fornecidas pelas escavações.

Sobre a aplicação destes materiais é importante registar algumas situações, como a separação dos tijolos de coluna em 3 tipos distintos, pois se, pela associação de 4,5 ou 6 elementos se obtinham circun- 
ferências regulares, aquando da construção pretendia-se o mesmo, um conjunto de tijolos de dimensões idênticas (corda, raio e espessura) tornando-a mais fácil. É razoável que quem encomendava este tipo de tijolos, o fazia para uma determinada construção, com dimensões exactas dos fustes das colunas, tendo ainda atenção ao facto de estas serem revestidas com argamassa ou estuque, com ou sem caneluras. Desta forma, os tijolos encontrados teriam uma dimensão concreta do diâmetro e altura do fuste para a realização de obras, levantando pela diversidade de dimensões, formatos e marcas, questões relacionadas com produções, produtores e oficinas.

Por outro lado, registam-se várias tipologias com uma utilização/aplicação mais diversificada (num maior número de edifícios), tais como os tijolos maciços rectangulares, tegulae e imbrices.

\subsection{Conservação e restauro dos materiais cerâmicos e estru- turas}

Sobre a conservação e reutilização destes materiais, Conimbriga é um local mais ou menos "pacífico", pelo facto de não existirem grandes construções totalmente em tijolo. Não se deve esquecer, no entanto, que os edifícios que foram usados durante muito tempo receberam alterações (demolições ou novas construções) e essas são testemunho de uma cronologia relativa (Adam, 1989; 163). Podem acrescentar-se ainda as catástrofes naturais, que implicam normalmente uma reconstrução. No caso de Conimbriga, podemos juntar a estas as invasões bárbaras, que a arrasaram, embora a cidade tenha continuado a ser habitada (Alarcão e Étienne, 1977; 9-10). É então provável que se tenham hoje algumas (re)construções desse período.

Desta forma, a problemática do restauro/reconstrução, e do que é exigido nos dias de hoje, assegurar a continuidade dos testemunhos arqueológicos, depara-se com uma questão pertinente: saberemos reconhecer e dar valor às reconstruções (entenda-se da época) e às actuais? Nomeadamente, no caso de Conimbriga, as designadas "consolidações" de estruturas efectuadas pela Direcção Geral dos Monumentos Nacionais, nem sempre bem documentadas. 


\section{BIBLIOGRAFIA}

ADAM, J. P. (1989) - La constrution romaine, Paris.

Alarcão, A. M. (1994) - Museu Monográfico de Conimbriga - Colecções, Lisboa, I. P. M.

Alarcão, J. (1988) - O Domínio Romano em Portugal, Mem Martins, Publicações Europa-América.

Alarcão, J. (1990) (dir.) - "O Domínio Romano em Portugal”, Nova História de Portugal (dir. Joel Serrão e A. H. Oliveira Marques), Lisboa, Editorial Presença, p. 345-489.

Alarcão, J. e ÉtIENNE, R. (1977) - "L'Architecture”, Fouilles de Conimbriga, Vol. I, Paris, Diffusion E. de Boccard.

ARrudA, A. M. (1988/89) - "Conimbriga: Escavações de 1988-89. 1. Algumas precisões sobre a cronologia do «bairro indígena»", Portugalia, Porto, Instituto de Arqueologia - F. L. U P., IX-X, p. 93-100.

ArrudA, A. M. (1997) - "Conimbriga: Fouilles de 1988-1989. 2. Les travaux sur le forum", Itinéraires lusitaniens, p. 13-33.

DiAs, L. (1999) - "Arquitectura com tijolos em Tongobriga: Estudo dos materiais das termas e dos aparelhos dos muros", Monografías de Arquitectura Romana, Madrid, 4, p. 277-290.

OCHOA, C. F., CERDÁn, A. M. e Prieto, M. Z. (1999) - "Material latericio en las termas romanas de Hispania", Monografías de Arquitectura Romana, Madrid, 4, p. 291-305 .

Santonja, J. A. G. (1999) - "El Alfar de Almadraba (Setla-Mirarosa-Miraflor) - Dianium - Materiales de construcción cerámicos. Producción y aproximación a su funcionalidad en la arquitectura del complejo artesanal", Monografías de Arquitectura Romana, Madrid, 4, p. 65-102. 